\title{
EDITORIAL
}

\section{A RELIGIÃO E SEUS DESDOBRAMENTOS}

Dando seguimento a linha editorial e ao volume 8 da Revista Relegens Thréskeia, prevaleceu a interdisciplinaridade, possibilitando que produções científicas qualificadas que dialogam com a ampla temática referente às religiões e suas implicâncias sociais tenham espaço e divulgação científica. Dessa maneira, este número é composto pela contribuição de pesquisadores de todas as regiões do Brasil, oriundos de diversas Instituições de Ensino Superior.

A publicação deste segundo semestre tem início com a contribuição do Dr. Paulo Rivera, professor do Programa de Pós-Graduação em Ciências da Religião da Universidade Metodista de São Paulo, e o Dr. Rogério Pamponet, também da Universidade Metodista de São Paulo. Ambos fazem uma análise sobre a interlocução do Papa Francisco com os movimentos populares, evidenciando a atenção do pontífice com os mais vulneráveis.

Diego Silveira, professor da Universidade do Estado da Amazônia, e presidente da Associação Brasileira de História das Religiões (ABHR), realiza uma análise a partir dos 300 anos do achamento da imagem de Nossa Senhora Aparecida, revisitando os significados e a importância desse acontecimento para a religião católica, a etnicidade e até mesmo para a identidade nacional nos dias atuais.

O professor da Universidade Federal do Amapá e pesquisador do CEPRES e GESCAM, Andrius Noronha, nos traz uma discussão acerca da identidade étnica e religiosa durante a primeira república, a partir de uma comunidade de imigrantes alemães na cidade de Santa Cruz do Sul, compreendendo o discurso germânico e o poder dos luteranos e suas redes, num ambiente preponderantemente católico.

José Neves Jr, doutorando em Ciências Sociais pela Universidade Estadual Paulista e pesquisador do grupo Pensamento Político Brasileiro e Latino-Americano e do Laboratório de Estudos sobre Religiões e Religiosidades (LERR), traz uma análise pontual das representações do conservadorismo contemporâneo em três obras de Antônio Ferreira Paim, buscando assim compreender o cerne político ideológico do filósofo brasileiro.

O professor do Instituto Federal de Goiás, Eliton Pereira e a Mestranda em Artes Márcia Trigueiro, trazem discussões exploratórias sobre a presença da indústria cultural no contexto da música religiosa, apontando também as contradições da cena gospel. 
O sociólogo Dr. Antonio L. Figueiredo Calou (UFRN), a psicóloga mestra Rivalina M. Maccedo Fernandes (UFPB) e o professor Rodrigo Brito de Almeida (UFCA) procuram explorar através dos conceitos da doutrina do Vale do Amanhecer, as perspectivas e visões sobre as categorias de sexualidade, colocando ênfase na homoafetividade.

Em seguida trazemos o trabalho do professor, mestre, e teólogo José Alves de Melo Neto, que faz uma análise que procura compreender e discutir a proposta educativa dos Oblatos de São José, uma congregação religiosa fundada pelo bispo italiano São José Marello (18441895), e como ela atua como proposta educativa sobre a integralidade da pessoa humana.

As pesquisadoras Dr ${ }^{a}$ Vanda Fortuna Serafim e Mestranda Mariene Rosa Emerenciano da Silva, da Universidade Estadual de Maringá (UEM) contribuem com uma análise do evento católico musical anual "Hallel” de Maringá. Buscam apreender como as narrativas do jornal local da cidade se assemelham ao que François Hartog (1999) define como "maravilhoso", sendo a procura por cativar os leitores sobre aquilo que está sendo narrado.

A próxima pesquisa, do Centro Universitário Uniihorizontes, composto pelo mestre e doutor Luciano Zille Pereira, mestrandas Chistienne Lopes Silva e Jaqueline dos Santos Teles, tem como objetivo analisar e descrever as vivências de prazer e sofrimento das freiras que exercem cargo de liderança em uma Congregação Católica localizada no estado de Minas Gerais. O artigo perpassa questões da psicologia, administração e religião.

Por fim, o trabalho do Dr. Rafael Parente Ferreira Dias (UFPB) e doutorando Marcello Renault Menezes (UFF), traz uma análise acerca da moralidade tendo como ponto de partida a influência do agir humano segundo Tomás de Aquino. O trabalho envolve questões sobre ética, fé e prudência, no que tange poder compreender os valores atribuídos ao comportamento humano.

Tendo isso em vista, o segundo número do volume 8 da Revista Relegens Thréskeia, finaliza o ano de 2019 reforçando as temáticas da interdisciplinaridade da pesquisa científica que perpassam o campo religioso.

Desejamos a todos(as) uma ótima leitura!

\author{
Vinícius dos Santos M. Bustos ${ }^{1}$ \\ Kaique Matheus Cardoso ${ }^{2}$ \\ pelo Conselho Editorial
}

\footnotetext{
${ }^{1}$ Mestrando em Sociologia pela Universidade Estadual de Londrina (UEL). Pesquisador e membro do grupo Laboratório de Estudos sobre Religiões e Religiosidades (LERR-UEL). E-mail. vini_bustos@hotmail.com

2 Doutorando em Sociologia pela Universidade da Beira Interior (Portugal). Pesquisador dos grupos de estudos NER-UBI e LERR-UEL. E-mail: cardosokm@gmail.com
} 